\title{
Revealing Possible Truths Behind "Coolest Monkey in the Jungle": Ideational Making Analysis Approach
}

\author{
Imam Khasbani \\ University of Bristol, United Kingdom \\ E-mail: imamkhasbany.2017@my.bristol.ac.uk
}

\begin{abstract}
Multimodal Critical Discourse Analysis (CDA)-commonly defined as a discourse analysis approach that focuses on both linguistic and non-linguistic resources- has been witnessing increasing popularity in the research area. It has been argued, on the one hand, that the greater level of practicality the approach has to offer compared to its predecessor (Critical Discourse Analysis) becomes the main reason of why researchers gradually turn their reference on analysing discourses to this method (Han, 2015). An increasing trend of multimodal communications - that no longer use speech or writing exclusively in their occurrences - has become the logical ground on the other (Kress, 2011). This paper, using H\&M 'monkey' hoodie advertisement (refer to appendix) as a form of multimodal communication, employs MCDA to explore the possible advantages one can learn through the process. To start with, a brief account of the key factors in the development of MCDA will be presented. This part is then followed by the discussion of the analysis approach employed in the paper and also the rational basis for choosing the approach over others. The analysis of the advertisement is done by drawing on related language and social theories to scrutinize the ideologies the company implanted on their advertisement. A thoughtful discussion on what is understood through the analysis process and what and how one can relate the practicality of multimodality analysis to another social area such as pedagogy will mark the end of this paper's discussion.
\end{abstract}

Keywords: Multimodality Critical Discourse Analysis; Controversial Advertisement; Racism; Advertisement Discourse

\section{INTRODUCTION}

For a long period of time, linguistics field had been preoccupied with the traditional view of language. Bybee and Hopper (2001) note that this view has contributed to the predominant presumption that the study of language bore no relationship to the social aspect in human life. The invention of grammar translation method and Saussure's (as cited in Koerner, 1971) concept of langue and parole - that have maintained language as a complex structure of abstract system that "can be separated from [parole]" (p.115) - have become a transparent proof how academicians at that time failed to see learning language as a part of social phenomenon (Xia, 2014). However, as the globalisation and the flow of people movement become more apparent that resulted in the more intercultural communications to occur and as the failure of grammar-based teaching method that created a situation where many language learners produced sentences that were "grammatically correct but unusual or even deviant in term of discourse rules" (Coulthard, 2014, p.146) the nature of language was once again contested. Hymes (1974) for example shows his rejection and frustrtaion by avowing that the traditional view of language "is indeed something of a contradiction, an irony at least, that we have today a general linguistics that justifies itself in term of understanding the distinctiveness of man, but has nothing to say, as linguistics, of human life"(p.147). 
Such an assertion becomes an obvious evidance of a shift perspective in understanding the complexion of human language where language that was earlier seen as an isolated abstract system is now treated as a product of intersectional social phenomena. This new standpoint has intrigued many men of knowledge to justify the relevancy of language and social practices. A considerable amount of works such as the work of Bremond on analysing the literature written by Vladimir Proop and the notorious analysis of Metz that looked into the language used in a film (van Dijk, 1985) had, since then, been centred on explaining monumental events on society by using language in use concept as their rational basis. These works successfully demonstrated the causal relationship between language use and society and also marked the rising trend of analysing language in use that is in its recent development often termed as "discourse analysis".

The root of discourse analysis goes a long way back to the work of critical linguistics by British linguists at the University of East Anglia at the end of the 1970s (Billig, 2008). Gunther Kress, one of the founders of this course of knowledge, speculates that linguistic features of a discourse act as an ideological tool to manipulate people's minds from which an everlasting effect on their behavior is expected (Machin \& Mayr, 2012). He argues that such control beliefs are facilitated because written language is semiotic resources that are almost always present in every culture and that its sign exhibits no arbitrary patterns of meanings (Bezemer \& Blommaert, 2013; Wodak, 2002). One can easily notice from the arguments that critical linguistic, albeit already touching upon the interrelationship aspect of language and its use in the wider social context, did not explain away how language was used to create an imbalanced state of dominance in a society. In other word, to borrow Fairclough's (1992) idea, critical linguistics failed to address the complexity of an ideology, power, and language relationship. At this point, critical discourse analysis (CDA) was invented as an alternative to fill the void critical linguistics brought into the process. CDA took a somewhat critical turn in the language analysis history by beginning to examine "structural relationship of dominance, discrimination, power and control" (Wodak, 2001, p.2) as well as a phenomenon of "solidarity with the oppressed" (van Djik, 2001, p.96) manifested in the textual discourse by taking into account "language and semiosis... within broader analyses of the social process" (Fairclough, 2001, p.121).

Still, despite all the features CDA has to offer, it did not go unchallenged. The rise of the information age marked by the changing trend from the traditional industry to the technology-based economy as an impact of the fast development of technology (Castells, 1997) changed the way people communicate with each other in the last few decades. The onset of this age has also been widely linked with digital revolution movement where the interactions among people become more and more abstract, in the sense that they do not involve physical contacts as much as they did before. This episode in the course of human life changes the way linguists understand the essence of communication. The way people interact with each other is argued to be always multimodal, involving various forms of semiotic codes (Djonov $\&$ Zhao, 2014). People can now easily gain an access to an abundance of pictures and videos in a matter of seconds. In a public area, it becomes scarce to find a communication-oriented discourse such as commercial texts or announcements that are produced without being illustrated. All advertising billboards on the road or flyers sent to mailboxes come with an interesting and colorful layout. Even warning signs in the highways telling us to reduce our car speed are written with a bright color to catch our attention. For that reason, the practice of CDA is often thought to be dangerous because not only it resulted in the impoverishment of discourse function, it also led to the extermination of other potential meanings of the text (O'Halloran, 2004). Multimodality Critical Discourse Analysis becomes a new rising trend in the discourse analysis area because its main programmatic feature is analysing multiple semiotic resources in a critical manner. MCDA has been widely applied in various discourses such as textbook, movie, music video, and advertisement. The latter has caught this paper attention because advertisement discourse is sometimes falsely thought to not have any ideological and political meaning in its practice. The thought might result from the standard regulation of today's advertisement that requires advertiser to "exhibit neutralisation of violence, pornography, attacking religious, and/or social values" (Koszembar-Wiklik, 2016, p.19). Nonetheless, such predominant thinking should be re-evaluated especially after all those controversial incidents happened to this commercialoriented discourse. It needs to bear in mind that no advertising activities is value-free and that there is 
always ideological motivation disguisedly inserted in advertisements.

\section{Ideational Making Analysis as an Approach in Analysing Advertisements}

Van Dijk (2001) warns those interested in conducting discourse analysis not exclusively to follow one particular method offered by a linguist. He further states that it is better to integrate the conceptions available from different perspectives and fields of knowledge. This argument becomes the paper's rationale in choosing Yuen (2004) approach for the advertisement analysis. Yuen's approach attempts to integrate Hasan's and Halliday's (1985) concept of general structure potential (GSP) on the advertisement with the theory of ideational meaning-making. The adaptation of GSP theory will be beneficial because this theory seeks to apprehend possible constructing components of a text genre and set the logical basis of the link between "preferred textual organization for text in a genre [and]... the social/communicative purpose that [the] genre sets out to achieve" (Olagunju, 2015, p.4). Although capture-focusjustification approach (1996) (as cited in Yuen, 2004) also offers a quite similar conception one could argue that the complexity of the advertisement elements has not yet become the central attention of the approach. This approach, to say in another word, fails to include elements other than images into its meaning-analysis process. GSP, on the other hand, already points out several components that make up an advertisement and a communicative relationship they possibly build on. Those elements are lead, emblem, announcement, enhancer, tag, and call-and-visit information.

Playing the most prominent role to catch people attention, lead refers to the size, quality and color selection of an image displayed in an advertisement. As an advertisement could contain of more than one image, lead is divided into two subcategories, which are Locus of Attention (LoA) and Complement of the Locus of Attention (Comp.LoA). As its name tells, $L o A$ acts as a main source of attention used in any commercial media. In printed advertisements, it usually points put to an image put in the centre of the layout. Often, if there are two or more images in the display, $L O A$ can be identified as the biggest or the most vivid one. On the other hand, as the supporting system of the main image Comp.LoA can usually be seen as other images in the advertisement that are place behind another image with a smaller size or blurry quality. As the main attraction of the commercial activity, lead plays a significant role in creating people' impression of the advertised products. Emblem can be simply denoted as a company logo or brandmark. It serves an identity, authenticity, and prestige purpose of an advertiser. By placing a logo, a car company is able to tell people that the car in the billboard belongs to them not to the company that might produce the same model of the product. A plain blouse might have the same value as any other blouses but as soon as we put Gucci brandmark its value and prestige will level up. Announcement is used to deliver the most important message of the product and usually comes with bigger, brighter, and shorter texts. Enhancer, on the contrary, projects information that is less silent in function, less inviting in feature and more longer in structure. Tag can be understood as all information that is not put in announcement and enhancer while call-and-visit information provides detail people can use to keep in touch with advertisers. The detail can be a website, email address, shop address, or telephone number where potential customers can refer to whenever they have something in mind regarding the company's products. The placements of the elements will be shown in the figure 1 .

From the figure, it is illustrative that each element of an advertisement discourse can be placed more than once. In the Asus advertisement, announcement and enhancer occur three times while the emblems appear in the two different locations. The advertiser, as one can argue, might see the need to promote two different products, the laptop and the operating system, and therefore they put two emblems to confirm both the identity and the originality of their product. The number of occurrence frequency of each element seems to depend on the purpose of the advertisement per se. On one occasion, for example, when the company does not acknowledge the significant of having interactions with potential customers, the absence of call-and-visit information element can be witnessed from their advertisement. While on another occasion, when an advertiser deliberately wants to create wider audiences' curiosity of the advertised products they will only employs emblem and lead in their flyers. The last occurrence, however, was witnessed by Yuen (2004) when analysing an advertisement from Guess company.

Although a more recent approach such as that of Machin and Mayr (2012) provides more discourse elements to analyse such as potent cultural symbol, tone, foregrounding, and overlapping it does not 
Figure 1. Advertisement elements structure of the Asus advertisement (the picture is retrieved from http://itfairsg.com)

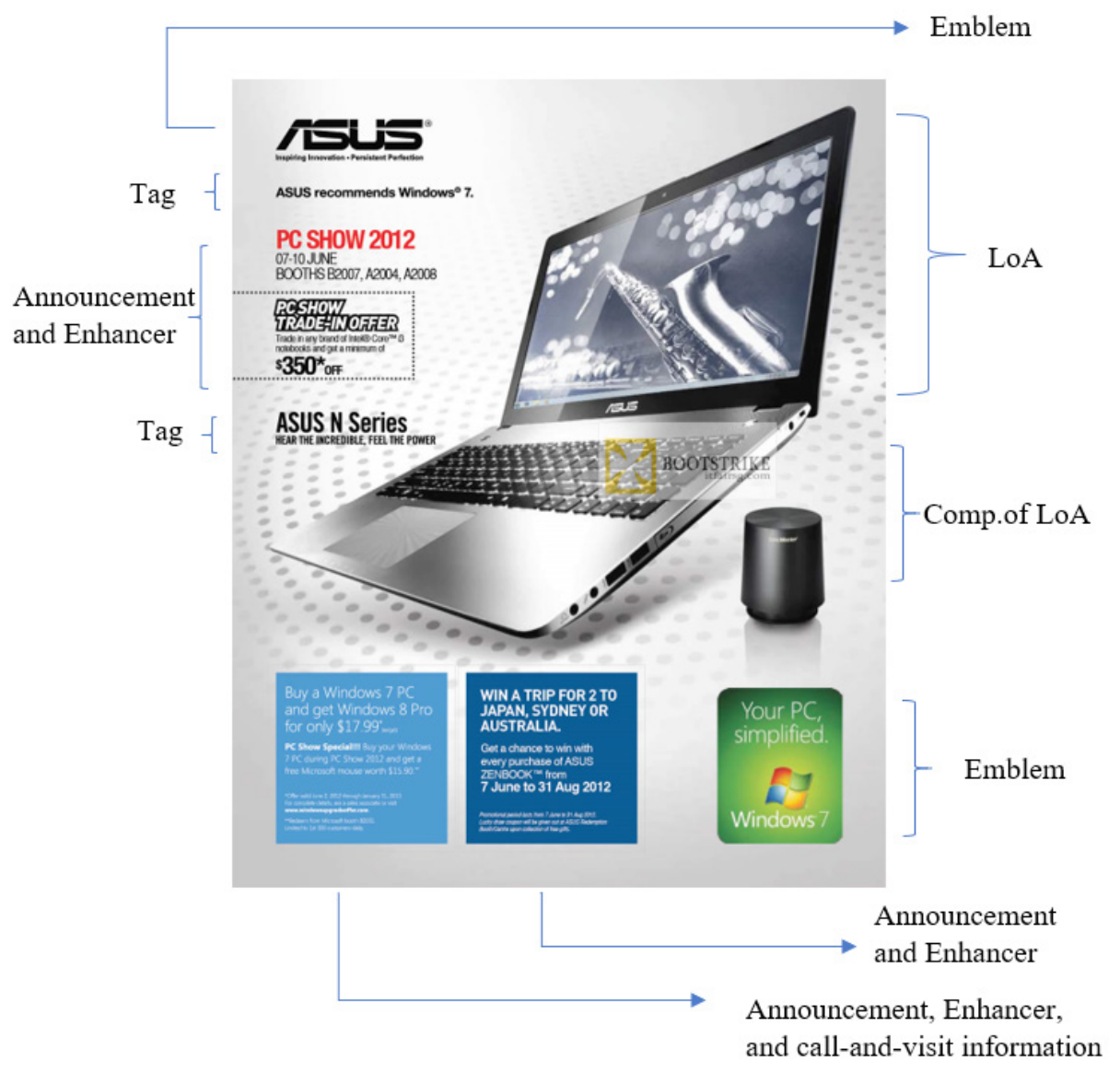

focus exclusively on advertisement discourse as Yuen's does. That said, Yuen's approach can be argued to offer a more in-depth analysis on an advertisement that is reflected in the process of the ideational making analysis. Bidirectional investment of meaning, Contextualization Propensity (CP), Interpretative Space (IS), and Semantic Effervescence (SE) are four strategic steps of the ideational making analysis. Bidirectional investment of meaning points out a meaning interpretation process by looking at the reciprocal relationship between lead and other features of an advertisement where the extent of that relationship is then described under the process of $\mathrm{CP}$ While IS and SE refer respectively to the interpretation degree and ambiguity level an advertisement can have in the meaning-making process. The ideological motivation reveals ideological (and political) motivations an advertisement tries to deliver to customers as well as contributing factors that lead to the advertisement's controversy (if happened).

\section{DISCUSSION OF THE ANALYSIS}

\section{Bidirectional Investment of Meaning in the H\&M “Monkey" Hoodie Advertisement}

Lead, as the most salient feature in the advertisement, was portrayed by H\&M in their advertisement as a black kid wearing a green hoodie. As the main role of lead is to catch the potential customer's attention, it is interesting to find out the company's motivation behind putting the African American kid as the model. Released to the public at the beginning of 2018, the H\&M advertisement was aimed at promoting their clothing product to their customers around the world. 
The United States as one of the company's big marketplace was exposed to the advertisement that the people in the country could access through the internet. As the the bi-directional relationship between a text and contextual setting and how a meaning-construct in the text becomes heavily circumstantial (Moore \& Tuckwell, 2006), it is getting obvious that the intention of displaying the black kid seems to show that the company uphold the value of equality- a seemingly everlasting issue of the country since its abolishment of slavery practices by the end $18^{\text {th }}$ century. Portraying such a model can also be translated as the company's intention to tell the public that the opportunity to become part of their teams is not restricted by racial factor and that diversity is placed in the forefront of the company value. This assumption is validated by the statement the company put in their website which says, "[w] hen we do business 'The H\&M Way' we do so ethically, honestly and responsibly" (H\&M, 2018). And as to the marketing strategies, this action can be regarded as a scheme to grab a wider consumer area. With over than 46 million people (United States Census Bureau, 2017), African-American population becomes a potential market for H\&M and using a model or an object (e.g., language) that represents a particular community in the company advertisement or service will likely attract people from that community to use the product. Psychologically expressed, this happening can be partially rationalized as homophily-a phenomenon where people tends to attract or be attracted by other people or things that share the same values or attributes as theirs (McPherson, Smith-Lovin, \& Cook, 2001)

Sentence structures, word choices, and colors can depict a possible meaning to people. By connecting visual code and the text or other resources, an interpretation of ideology is able to glean. H\&M's decision to put coolest monkey in the jungle on a hoodie modelled by a black kid can be interpreted as an effort to attract sympathy from wider audiences. They attempt to build a positive image by subtly narrating that being cool can apply to all people from all races while at the same time also trying to emphasize the value they put in the announcement by using hoodie as the representation. The consent of hoodie as a token of youth, bravery, and coolness (Ray, 2017), though oversimplified and occasionally misleading because in some social contexts it is closely related with a tendency of crime, seems to be widely accepted. By putting the word coolest in the hoodie, H\&M wants to tell all the young kids that the desire of identity values they yearn for can be satisfied by using their product. The use of the superlative form of the adjective "cool" can also be interpreted that the company is trying to convince the potential buyers that their hoodie can make them stand out from others, or in other word become the best. The phenomenon of a company trying to convince people that their product is the best becomes very common in marketing strategies. A rationale ground to help explain this occurrence might come from the fact that the need of competence as described by Deci and Ryan (2000) in their self-determination theory is already invested in human innate psychological need. People are determined to present themselves as the best among others by nature and they will use material resources as the medium of self-actualization. The resources, thus, have to be the best and different or perceived in such way by general societies. That explains why many companies try to build up such a perception by having an appealing slogan such as "Think Different" (Apple Inc.), "Made like no other" (Häagen-Dazs), or "Coolest Monkey in the Jungle" $(H \& M)$. Regarding the use of green as the hoodie color, one can easily assume that it is aligned with the word "coolest" and the hoodie itself; it is used to signify the value of youthfulness (Bogushevskaya \& Colla, 2015). Additionally, the color can be read as a reference to the word jungle. However, as the representation of colors is heavily culture-specific (e.g., red represent luckiness in Chinese context while it is a sign of bad luck and anger in other settings), one cannot precisely translate this semiotic code and make a generalization out of it.

In addition to the elements mentioned above, other features of the advertisement can also enrich the meaning-making process. The placement of H\&M emblem in the advertisement is used to validate that the product displayed is authentically fabricated by the company with its standard of production. And as the H\&M's advertisement was created under an online platform it also acts to help us single out the authenticity of the website we are visiting, although in a real practice we cannot solely rely on a website logo for this matter. The top and the central position of the emblem signifies the advertiser's intention to make the logo easier to see. The research-based articles written by Nielsen (2006; 2010a; 2010b), nevertheless, contested this position. They speculated that people speaking left-to-right languages would spend more than twice of their time focusing on the information available at the top left side of a webpage while 
those speaking right-to-side language will focus on the top right part. An assertion as such explains why English language website such as Bristol University (http://www.bristol.ac.uk) and Amazon (https://www. amazon.co.uk) put the logo in the top left corner while BBC written in Arabic language (http://www.bbc.com/ arabic) places the emblem in the top left corner. Then why does H\&M violate this traditional convention? Conjectures to offer are because the company might intend to bring into open the concept of being different and because they possibly subscribe to the idea that "[a] sustainable company... are pressing forward and trying out new metrics. Rather than letting the metrics challenges stall their progress." (Eccles, Perkins, \& Serafeim, 2012, p.48). Furthermore, the small size of the logo might resonate the belief that "the brand logo should be subtle" (Pessala, 2016, p.25) so that it does not create overlapping attention with the lead.

Navigation bars and picture thumbnails can also be an interesting source for the analysis. Yuen (2004) did not include these features in her work but as she mentioned that the advertisement discourse is "restlessness" and "metamorphose along with changes in society" (p.175) analyzing these two features is considered useful because it is almost impossible not to find these features in today's website-based advertisement. An argument to offer regarding the placement of these elements is that H\&M want to provide the costumers an enjoyable shopping experience. With the need to do purchasing activities with ease becomes the main driving of online shopping (Shanthi \& Kannaiah, 2015), navigation bars can facilitate such a need by giving a facility to look through various products by just moving their fingertips. Picture thumbnails, similarly, can also provide ease to customers by giving them a quick preview without having to click the images.

With all the analyses done in the above discussion, a final judgment can be agreed upon the H\&M advertisement is that the company is willing to reach a broader market of customers by upholding the value of equality and other 'good' values in society while at the same time providing a pleasant shopping experience. However, the company received a somewhat contradicting experience after their advertisement received a storm of protests and an accuse of being racist. Intriguing questions to ask now is "How can this episode happen? Are not all the advertisement elements put in neutralization just like the standard regulation tell us to do?'

\section{Contextual Prosperity, Interpretative Space and Semantic Effervescence: the "Coolest Monkey" that is not "Cool."}

In the beginning of January 2018, the H\&M company came under fire after a storm of critiques and outrages were widely spread by online shoppers who encountered one of the clothing-retail company's advertisements portraying a black kid as the model with "Coolest Monkey in the Jungles" tagline printed on the hoodie he is wearing (Linning \& Gordon, 2018, January). The following accusation of being racist and insensitive of the black community was strongly aimed at this multinational commercial business. H\&M had to face even bigger backlashes when influential figures in the entertainment industry such as The Weeknd, G-Eazy, Jesse Williams, and LeBron James decided to join the "ally" to denounce the advertisement bias (Barogana, 2018). Although the defending action claiming that the advertisement was not intentionally racist and that the protests were unnecessary had later been made by the kid's mother (Pemberton, 2018), it failed to save the company from the trouble. An unprecedented impact on the broader social setting can be witnessed in Johannesburg, South Africa when protesters from The Economic Freedom Fighters joined together to voice their disapproval causing chaos and destruction in six H\&M stores (Winning, 2018). This phenomenon, then, becomes an excellent example of what Yuen define in her work as Contextual Prosperity.

Yuen (2004) defines Contextual Prosperity (CP) as "the degree to which linguistics item in a print advertisement contextualize the meaning of the visual images" (p.176). The degree of correspondence between linguistic and visual denotes the extent of participants' interpretation and contextualization in the meaning-making process. CP builds an opposite relationship with Interpretative Space (IS) and Semantic Effervescence (SE). That said, the higher the level of interconnectedness between texts and images in the advertisement the more definable the relationship, the narrower the construal, and the less ambiguous message can be established. On the other hand, less textual resources in the advertising discourse will open more spaces to varied interpretations that may not align with that of the advertiser. In the H\&M advertisement, the lead comes with rather very few number of linguistic codes. The announcement comes with fragmented sentences ("Printed Hooded Top" and "Coolest Monkey in the Jungle") while the 
enhancer focuses heavily on the purchasing process and detailed information on clothing materials. We can argue that the advertisement has a low level of $\mathrm{CP}$ that lead to a broader interpretation and a higher degree of ambiguity level. While this formation can make the advertisement look neat and focus more on describing the quality of the advertised products, it can invite unintended gaffes that might pose a threat to the credibility of product and company.

The facts that language and culture are two complementary and inseparable social aspectslanguage culture (Risager, 2005) - and that the way people perceive the world is heavily influenced by the language they speak- linguistic relativity (Lucy, 1997) - set a clear account how words (or phrases) that mainly do not denote a negative meaning can exert a utterly different understanding when placed alongside certain semiotic elements in different settings. Gee (2011) in a similar manner maintains that "words and phrases take on much more specific meaning in actual contexts of use" (p.23). The word "pig", for example, does not connote negative meaning in some Western societies thanks to "a recognition of the unique position of the pig in Judeo-Christian Western culture" (Komins, 2001, p.9) but receive a derogatory perception in Indonesian context where Islamic values play a vital role in creating the cultural perception that the animal is prohibited to eat, and one would commit a sin if breaking the rule (Nurpadillah, 2017). The 'pig' word tells us that a word can bring a potential level of taboo from which a negative connotation is derived (Leach, 1964), and this negative value is then translated as a 'label' in a society. Label itself, as Smith (1992) posited, is of importance due to its ability to regulate social standing of a group of people to which the label is attached. The power of label can bring people up into or drag them down from a certain level of social stratification.

Regarding the word "monkey," it could exhibit a very offensive label when it is put within a black community context. The history records that "monkey" was a racial slur used to deride people of African descendant, which result from a false belief accusing the people to be closely related to monkey genetically and physically (Arkande, 2016). The word has also put black people community in a situation where they feel unappreciated and alienated from the peripheral surroundings (Hairstone, 2008). With that all said, putting the word "monkey" in the advertisement alongside with a black kid as the model could undoubtedly trigger ambivalent interpretations in spite of the advertiser's initial intention that might not be deliberately racist. Additionally, the lack of linguistic and visual resources in the advertisement could also be another factor to blame for the controversy. Yuen (2004) warned that "without the contextualizing function of linguistic items, the Lead... has a bounty, a kaleidoscope of meaning and has great meaning potential" (p.188). Had the advertiser put more semiotic resources, i.e., placing a picture of a white kid putting on the same hoodie next to the black model or changing the word 'monkey' into another word that connote no derogative meaning to black and any community like 'lion' or 'tiger', the society interpretation of the advertisement would have been more linear to that of the company's.

\section{The Practical Relevance of Multimodality Critical Discourse Analysis: Reflective Conclusion}

The above discussion has shown us how MCDA can help reveal the ideological and political motivation manifested in the advertisement discourse while at the same time can be a 'magical tool' for companies to save the entrepreneurship affairs. Having adequate knowledge to critically analyse the contexts where our business will take place will not only save us from unnecessary vague interpretations like that of H\&M's on racism or other companies and products such as Dove on beauty standards (Goins, 2016), Axe on sexuality (Sugiarto \& Barnier, 2013) and Trojan on masculinity (Katz, 2003) but also prevent our commercial enterprises from negative effects that can potentially kill the business venture However, the importance of discourse analysis, as one should note, is not limited only to commercial enterprise. The functionality of this language in use analysis can be extended to the practical area of language teaching and pedagogy. Often, this practicability falls under the term of "practical relevance" (van Djik's, 1985, p.4). The relevances MCDA can promote in relation to language learning and teaching process are critical digital literacy and language awareness.

The consensus of the essence of critical language literacy in today's digital revolution era where information and communication technology are present in almost all parts of the education system (UNESCO, 2011) seems to be widely validated. With more learning resources being digitalized the need to have critical digital literacy- the ability to critically select and use online (and offline) digital resource (Lankshear \& Knobel, 2006) - becomes 
uncompromisingly essential. With rather large and unlimited amount of language resources available on the internet today, finding tailor-made learning resources can be challenging. MCDA, by providing basic skill learners needed to decode language used in the digital resources like "interpretation and recognizing unstated assumption" (Hashemi \& Ghanizadeh, 2012, p.43) enables students to evaluate the validity of online material they found on the internet. These skills are also expected to be translated into wider educational and social context of students' lives when they have to deal with discursive arguments or discourses. As the next practical relevance, language awareness is commonly claimed to benefit learners with "the ability to understand how language affects human life and... [the skill] of crosscultural understanding" (Ellis, 2012, p.3). With crosscultural interaction to occur more often as an impact of international communication that has never been easier the need of what Wertsch (1985) (as cited in Rowe, 2011) labeled as strategic activity-the ability to perform successfully in the sociocultural participation - has gathered its own momentum. MCDA at this point helps learners tackle such challenge by promoting cultural awareness from its critical analysis activities By critically analyzing textual, visual and other forms of semiotic resources learners can potentially build up both their linguistic and socio-cultural knowledge of the context within which the language is operated which they can later implement on their daily communicative activities.

The functionality of multimodality analysis can, furthermore, promote teachers' awareness of learners' cultural background in relation to multimodality literacy. The ability to adapt and synthesize possible ideologies deep-rooted in multimodality learning resources with local values reflected in the political mandates has become a critical need for educators in today's fast-changing communication technology (Walsh, 2010). One could easily argue that the lack of such skill could not only bring detrimental effect to the classroom activities where students' learning are not fully facilitated but could also raise a farreaching social tension. Verifiable examples are what happened on English textbooks in some countries such as Indonesia (Indrawan, 2017) where one of the country's English workbook was blamed for being culturally inappropriate for showing communism symbol and America (Sini, 2017) whose one of the country infamous publishers received protests after posing racial stereotype on their textbook. These examples once again emphasize the importance of having such critical analysis skill in choosing culturally appropriate learning resources for the classroom activities. Not only should teachers pay their attention to the content of learning resources they also should not neglect the impact the material coud possibly bring into the local society.

\section{APPENDIX}

Appendix 1. The H\&M "Coolest monkey in the jungle" advertisement (the picture is retrieved from https:// www.theatlantavoice.com/wp-content/uploads/2018/01/8F1FF55C-BD97-4D05-822D-2D64AC8A4D5B.jpeg)

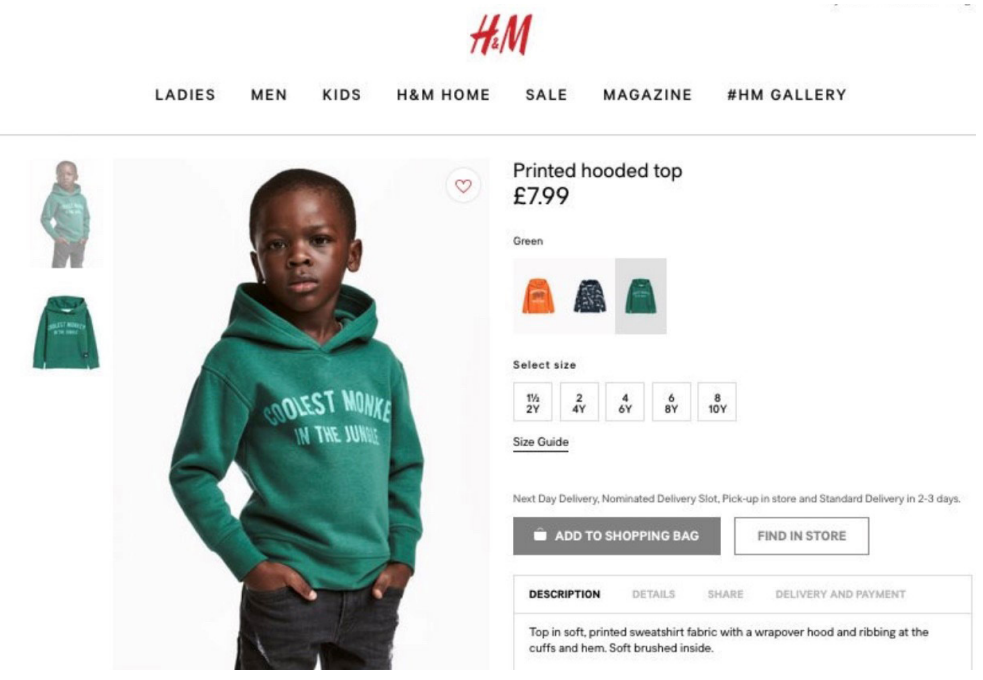




\section{REFERENCES}

Arkande, H. (2016). Illuminating the Blackness: Blacks and African Muslims in Brazil . London: Rabaah Publishers.

Barogana, L. (2018, January 10). 6 Celebrities Who Denounced H\&M after It Used a Black Child to Sell a 'Racist'Shirt. Insider. Retrieved on February 06, 2018, from http://www.thisisinsider.com/ celebrities-react-hm-monkey-sweatshirt-2018-1.

Bezemer, J., \& Blommaert, J. (2013). Kress, Gunther. In C. A. Chapelle (Ed.), The Encyclopedia of Applied Linguistics (pp. 2901-2905). New Jersey: Blackwell Publishing Ltd.

Billig, M. (2008). The Language of critical Discourse Analysis: The Case of Nominalization. Discourse \& Society, 783-800.

Bogushevskaya, V., \& Colla, E. (2015). Thinking Colors: Perception, Translation and Representation. Newcastle Upon Tyne: Cambridge Scholars Publishing.

Butler, C. S. (2003). Structure and Function: A Guide to Three Major Structural-Functional Theoris Part 2: From Clause to DIscourse and Beyond. Philadelphia: John Benjamins Publishing Company.

Bybee, J., \& Hopper, P. (2001). Introduction to Frequency and the Emergence of Linguistic Structure. In J. Bybee, \& P. Hopper (Eds.), Frequency and the Emergence of Linguistic Structure (pp. 1-26). Philadelphia: John Benjamins Publishing Company .

Castells, M. (1997). An Introduction to the Information Age. City, 6-16.

Coulthard, M. (2014). An Introduction to Discourse Analysis (Second ed.). (C. N. Candlin, Ed.) New York: Routledge.

Deci, E. L., \& Ryan, R. M. (2000). The "What" and "Why" of Goal Pursuits: Human Needs and Self-Determination of Behaviour. Psychological Inquiry, 227-268.

Djonov, E., \& Zhao, S. (2014). From Multimodal to Critical Multimodal Studies through Popular Discourse. In E. Djonov, \& S. Zhao (Eds.), Critical Multimodal Studies through Popular Discourse (pp. 1-16). New York: Routledge.

Eccles, R. G., Perkins, K. M., \& Serafeim, G. (2012). How to Become a Sustainable Company. MIT SLoan Management Review, 42-50.

Ellis, E. M. (2012). Language Awarness and Its Relevence to TESOL. University of Sydney Papers in TESOL, 1-23.

Fairclough, N. (1992). Discourse and Social Change. Cambridge: Blackwell Publishing Ltd.
Fairclough, N. (2001). Critical Disclouse Analysis as a Method in Social Scientific Research. In Methods of Critical Discourse Analysis (pp. 121-138). London: Sage Publications.

Gee, J. P. (2011). Discourse Analysis, What Makes It Critical? In R. Rogers (Ed.), An Introduction to Critical Discourse Analysis in Education (pp. 2345). New York: Routledge.

Goins, K. E. (2016). Dove Campaing for Real Beauty (master thesis). Alabama: University of Alabama.

H\&M. (2018). The H\&M Way. H\&M. Retrieved on February 12, 2018, from https://about.hm.com/ content/dam/hmgroup/groupsite/documents/en/ hm-way/HM\%20Way_en.pdf.

Hairstone, K. R. (2008). Dehumanization of the Black American Female: An American/ Hawaiian Experience. Space for Difference: An Interdisciplinary Journal , 65-85.

Han, C. (2015). How to Do Critical Discourse Analysis: A Multimodal Introduction. Australian Journal of Linguistics, 415-418.

Hashemi, M. R., \& Ghanizadeh, A. (2012). Critical Discourse Analysis and Critical Thinking: An Experimental Study in an EFL Context. System, 37-47.

Hodge, R., \& Kress, G. (1988). Social Semiotics. New York: Cornell University Press.

Hymes, D. (1974). Foundations in Sociolinguistics: An Ethnographic Approach. London: Tavistock Publication Limited.

Indrawan, A. (January 23, 2017). Ini Kronologi ditemukannya Buku Kisi-Kisi UN Bergambar Palu-Arit. Republika. Retrieved on February 12, 2018, from http://www.republika.co.id/ berita/nasional/hukum/17/01/23/ok85zc365ini-kronologi-ditemukannya-buku-kisikisi-unbergambar-paluarit.

Katz, J. (2003). Advertising and the Construction of Violent White Masculinity: From Eminem to Clinique for Men. In G. Dines, \& J. M. Humez (Eds.), Gender, Race and Class in Media: A Text Reader (Second ed., pp. 349-358). California: Sage Publications.

Koerner, E. F. (1971). Ferdinand De Saussure: Origin and Development of His Linguistic Theory in Western Studies of Language (Doctoral Dissertation). British Columbia: Simon Fraser University.

Komins, B. J. (2001). Western Culture and the Ambigous Legacies of the Pig. CLCWeb: Comparative Literature and Culture, 1-10.

Koszembar-Wiklik, M. (2016). Controversional Themes in Advertisments: On Manipulating the Emotion of Audiences and Extending the Boundaries of 
the Social 'Taboo'. Communication Today, 18-31. Kress, G. (2011). Discourse Analysis and Education: A Multimodal Social Semiotic Approach. In R. Rogers (Ed.), An Introduction to Critical Discourse Analysis in Education (Second ed., pp. 205-226). New York: Routledge.

Lankshear, C., \& Knobel, M. (2006). Digital Literacy and Digital Literacies: POlicy, Pedagogy and Research Consideration for Education. Digital Kompetanse, 12-24.

Leach, E. (1964). Anthropological Aspects of Language: Animal Categories and Verbal Abuse. In E. H. Lenneberg (Ed.), New Directions in the Study of Language (pp. 23-63). Massachusetts: The M.I.T. Press.

Linning, S., \& Gordon, A. (2018, January 08). Critics Call for Boycott of H\&M over Advert for 'Coolest Monkey in the Jungle' Child's Hoodie Featuring a Black Model. Daily Mail. Retrieved on February 06, 2018, from http://www.dailymail.co.uk/news/ article-5245887/Critics-call-boycott-H-M-racistadvert.html.

Lucy, J. A. (1997). Linguistic Relativity. Annu. Rev. Anthropol, 291-312.

Machin, D., \& Mayr, A. (2012). How to Do Critical Discourse Analysis. London: Sage Publications Ltd.

Machin, D., \& Mayr, A. (2012). How to Do Critical Discourse Analysis: A Multimodal Introduction. Thousand Oaks, California: Sage Publications Inc.

McPherson, M., Smith-Lovin, L., \& Cook, J. M. (2001). Birds of Feather: Homophily in Social Networks. Annu. Rev. Sociol., 415-444.

Moore, A., \& Tuckwell, K. (2006). A Tenorless Genre? Forensic Generic Profiling of Workers' Compensation Dispute Resolution Discourse. Linguistics and Human Sciences, 205-232.

Nielsen , J. (2006). F-Shaped Pattern for Reading Web Content (Original Study). Retrieved on 5 February, 2018, from https://www.nngroup.com/ articles/f-shaped-pattern-reading-web-contentdiscovered/.

Nielsen, J. (2010b). Scrolling and Attention. Retrieved on 5 February, 2018, from https://www.nngroup. com/articles/scrolling-and-attention/.

Nielsen, J. (2010a). Horizontal Attention Leans Left (Early Research). Retrieved February 5, 2018, from https://www.nngroup.com/articles/ horizontal-attention-original-research/.

Nurpadillah, V. (2017). Wacana Kepemimpinan: Analisis Makna Konotasi Dalam Teks Pidato Perdana Presiden Jokowi. Jalabahasa, 83-92.

O’Halloran, K. L. (2004). Multimodal Discourse
Analysis: Systemic Functional Perspective. New York: Continuum.

Olagunju, S. (2015). Generic Structure Potential of Football Matches in Newspaper Reporting. IOSR Journal of Humanities and Social Science, 38-50.

Pemberton, B. (January 16, 2018). Racism Row: Who is Liam Mango, What is the H\&M Monkey Hoodie 'Racist' Advert Row and What's His Mum Terry Said? The Sun. Retrieved on February 02, 2018, from https://www.thesun.co.uk/ fabulous/5342604/liam-mango-hm-monkeyhoodie-racist-advert/.

Pessala, I. (2016). User Experience and Efficiancy of Instagram Advertising (Bachelor's Thesis). Jyväskylä, Finland: JAMK University of Applied Science.

Ray, R. (2017). "If Only He Hadn't Worn the Hoodie...": Race, Selective Perception, and Streotype Maintenance. In S. M. McClure, \& C. A. Harris (Eds.), Getting Real abput Race: Hoodies, Mascots, Model Minoroties, and Other Conversations (Second ed., pp. 72-84). California: Sage Publications, Inc.

Risager, K. (2005). Languaculture as a Key Concept in Language and Culture Teaching. In B. Preisler, A. Fabricius, H. Haberland, S. Kjærbeck, \& K. Risager (Eds.), The Consequences of Mobility: Linguistic and Sociocultural Contact Zones (pp. 185-196). Roskilde, Denmark: Roskilde Universitet.

Rowe, S. (2011). Discourse in Activity and Activity as Discourse. In R. Rogers (Ed.), An Introduction to Critical Discourse Analysis in Education (Second ed., pp. 227-241). Newyork: Routledge.

Shanthi, R., \& Kannaiah, D. (2015). Consumer's Perception on Online Shopping. Journal of Marketing and Consumer Research, 14-20.

Sini, R. (October 20, 2017). Publisher Apologises for 'Racist' Text in Medical Book. BBC. Retrieved on February 12, 2018, from http://www.bbc.co.uk/ news/blogs-trending-41692593.

Smith, T. W. (1992). Changing Racial Labels: From "Colored" to "Negro" to "Black" to "Afrocan American”. The Public Opinion Quarterly, 496514.

Sugiarto, C., \& Barnier, V. D. (2013). Sexually Appealing Ads Effectiveness on Indonesian Customers . European Journal of Business and Management , 125-135.

Tannen, D. (n.d.). Discourse Analysis-What Speakers Do in Conversation. Retrieved January 31, 2018, from https://www.linguisticsociety.org/ resource/discourse-analysis-what-speakers-doconversation. 
UNESCO. (2011). Digital Literacy in Education. Retrieved from http://unesdoc.unesco.org/ images/0021/002144/214485e.pdf

United States Census Bureau. (2017). National African American History Month: February 2017. Retrieved on February 12, 201, from https://www. census.gov/content/dam/Census/newsroom/ facts-for-features/2017/cb17-ff01.pdf.

van Dijk, T. A. (1985). Introduction: Discourse Analysis as a New Cross-Discipline. RSE Analysis, 1-10.

van Djik, T. A. (2001). Mutidisciplinary CDA: A Plea for Diversity. In R. Wodak, \& M. Meyer (Eds.), Methods of Critical Discource Analysis (pp. 95120). London: Sage Publications.

van Djik, T. A. (1985). Handbook of Discourse Analysis, Volume 4: Analysis in Society. Massachusetts: Academic Press.

Walsh, M. (2010). Multimodal Literacy: What does It Mean for Classroom Practice? Australian Journal of Language and Literacy, 211-239.
Winning, A. (2018, January 13). Protesters Attack H\&M Stores and Tear Down Shop Displays over 'Racist' Advert. Mirror. Retrieved on February 06, 2018, from https://www.mirror.co.uk/news/worldnews/protesters-attack-hm-stores-tear-11847020.

Wodak, R. (2001). What CDA is about-a Summary of Its History, Important Concepts and Its Developments. In R. Wodak, \& M. Meyer (Eds.), Methods of Critical Discourse Analysis (pp. 1-13). London: Sage Publications.

Wodak, R. (2002). Aspects of Critical Discourse Analysis. ZfAL, 5-31.

Xia, Y. (2014). Language Theories and Language Teaching: From Traditional Grammar to Functionalism . Journal of Language Teaching and Research, 559-565.

Yuen, C. Y. (2004). The Construal of Ideational Meaning in Print Advertisement. In K. L. O'Halloran (Ed.), Multimodal Discourse Analysis: Systemic Functional Perspectives (pp. 163-195). New York: Continuum. 